\title{
SOME INEQUALITIES ON SUBLINEAR FUNCTIONALS RELATED TO THE INVARIANT MEAN FOR DOUBLE SEQUENCES
}

\author{
M. Mursaleen And S. A. Mohiuddine
}

Abstract. In this paper we define invariant mean for double sequences and construct a sublinear functional which dominates and generates invariant mean.

Mathematics subject classification (2010): 40C05, $40 \mathrm{H} 05$.

Keywords and phrases: Double sequences, $P$-convergence, invariant mean, $\sigma$-convergence.

\section{REFERENCES}

[1] B. Altay And F. BAŞAR, Some new spaces of double sequences, J. Math. Anal. Appl., 309 (2005), 70-90.

[2] C. ÇAKan, B. Altay And M. Mursaleen, The $\sigma$-convergence and $\sigma$-core of double sequences, Appl. Math. Lett., 19 (2006), 1122-1128.

[3] A. GÖKhan And R. ÇOLAK, The double sequence spaces $c_{2}^{P}(p)$ and $c_{2}^{P B}(p)$, Appl. Math. Comput., 157 (2004), 491-501.

[4] A. GÖKhan And R. ÇOLAK, The double sequence spaces $l_{2}^{\infty}(p)$, Appl. Math. Comput., 160 (2005), 147-153.

[5] H. J. Hamilton, Transformations of multiple sequences, Duke Math. J., 2 (1996), 29-60.

[6] G. G. LoREntz, A contribution to theory of divergent sequences, Acta Math., 80 (1948), 167-190.

[7] F. MORICZ AND B. E. RHOADES, Almost convergence of double sequences and strong regularity of summability matrices, Math. Proc. Camb. Phil. Soc., 104 (1988), 283-294.

[8] M. Mursaleen and Osama H. H. Edely, Almost convergence and a core theorem for double sequences, J. Math. Anal. Appl., 293 (2004), 532-540.

[9] M. Mursaleen And E. SAVAŞ, Almost regular matrices for double sequences, Studia Sci. Math. Hung., 40 (2003), 205-212.

[10] M. Mursaleen And S. A. Mohiuddine, Double $\sigma$-multiplicative matrices, J. Math. Anal. Appl., 327 (2007), 991-996.

[11] M. Mursaleen And S. A. Mohiuddine, Regularly $\sigma$-conservative and $\sigma$-coercive four dimensional matrices, Comput. Math. Appl., 56 (2008), 1580-1586.

[12] M. Murs AleEn, On some new invariant matrix methods of summability, Quart. J. Math. Oxford, 34 (1983), 77-86.

[13] M. MuRSALEEN, Almost strongly regular matrices and a core theorem for double sequences, J. Math. Anal. Appl., 293 (2004), 523-531.

[14] R. F. PAtterson, Double sequence core theorems, Internat. J. Math.\& Math. Sci., 22 (1999), 785793.

[15] A. Pringsheim, Zur theorie der zweifach unendlichen Zahlenfolgen, Math. Z., 53 (1900), $289-321$.

[16] G. M. Robinson, Divergent double sequences and series, Trans. Amer. Math. Soc., 28 (1926), 5073.

[17] M. Zeltser, Matrix transformations of double sequences, Acta Comment. Univ. Tartu Math., 4 (2000), 39-51. 